\title{
Brief Communication: CATALYST - a multi-regional stakeholder think tank for fostering capacity development in disaster risk reduction and climate change adaptation
}

\author{
M. P. Hare ${ }^{1}$, C. van Bers ${ }^{1}$, P. van der Keur ${ }^{3}$, H. J. Henriksen ${ }^{3}$, J. Luther ${ }^{6}$, C. Kuhlicke ${ }^{6}$, F. Jaspers ${ }^{7}$, C. Terwisscha van

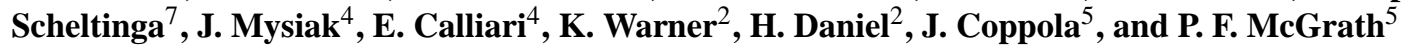 \\ ${ }^{1}$ seeconsult GmbH, Osnabrück, Germany \\ ${ }^{2}$ United Nations University, Institute for Environment and Human Security (UNU-EHS), Bonn, Germany \\ ${ }^{3}$ Geological Survey of Denmark and Greenland (GEUS), Department of Hydrology, Copenhagen, Denmark \\ ${ }^{4}$ Fondazione Eni Enrico Mattei (FEEM), Venice, Italy \\ ${ }^{5}$ The World Academy of Sciences (TWAS) for the advancement of science in developing countries, Trieste, Italy \\ ${ }^{6}$ Helmholtz Centre for Environmental Research (UFZ), Department of Urban and Environmental Sociology, \\ Leipzig, Germany \\ ${ }^{7}$ Alterra, Wageningen, the Netherlands
}

Correspondence to: M. P. Hare (mhare@ seeconsult.org)

Received: 12 February 2013 - Published in Nat. Hazards Earth Syst. Sci. Discuss.: 8 August 2013

Revised: 12 March 2014 - Accepted: 13 May 2014 - Published: 22 August 2014

\begin{abstract}
This brief communication presents the work and objectives of the CATALYST project on "Capacity Development for Hazard Risk Reduction and Adaptation" funded by the European Commission (October 2011-September 2013). CATALYST set up a multi-regional think tank covering four regions (Central America and the Caribbean, East and West Africa, the European Mediterranean, and South and Southeast Asia), intending to strengthen capacity development for stakeholders involved in disaster risk reduction (DRR) and climate change adaptation, in the context of natural hazards. This communication concludes with a selection of recommendations for capacity development in DRR and climate change adaptation from the perspective of governance issues.
\end{abstract}

\section{Project context and objectives}

The CATALYST project (October 2011-September 2013), funded by the European Commission Seventh Framework Programme (FP7), was set up in part to address a specific gap (Jaspers et al., 2012), a gap most recently identified by the International Panel on Climate Change (IPCC) special report on extreme events (IPCC, 2012) that although we have substantial knowledge to improve the management of climate risks, this knowledge is not taken advantage of often enough. CATALYST follows on from earlier EU coordination actions on natural hazard risk reduction, e.g. CapHaz-Net (see Kuhlicke et al., 2011), and is intended to strengthen capacity development available to stakeholders involved in disaster risk reduction (DRR) in the context of natural hazards (see UNISDR (2009) for relevant definitions). Since many of these hazards are driven by current and future climate variability, it also addresses climate change adaptation (CCA). The project sought, with the support of knowledgeable regional experts, to compile and analyse the best of knowledge from four regions of the world, in order to develop knowledge products useful to practitioners from diverse sectors.

CATALYST deals with natural hazards, both hydrometeorological (cyclones, droughts, heat waves, wildfires, storm surges, and floods) often aggravated by climate change, and geological hazards (earthquakes, tsunamis, and landslides). As mentioned, the project focused on four regions: Central America and the Caribbean, East and West Africa, the European Mediterranean, and South and Southeast Asia (see Fig. 1). 


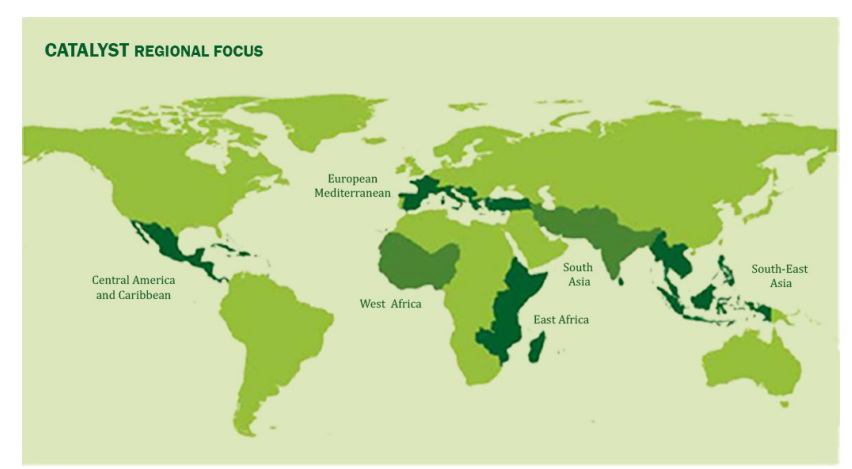

Figure 1. The CATALYST regions (Jaspers et al., 2012).

The ultimate goal was to share and bring knowledge of disaster risk management to bear on economic development, water resource management, and land-use planning issues, and to make DRR and CCA critical components of the sustainability agenda (see O'Brien et al. (2008) for an explanation of the importance of doing so). CATALYST adopts the UNISDR definition of capacity development - i.e. the process by which people, organisations and society systematically stimulate and develop their capability over time to achieve social and economic goals, including through improvement of knowledge, skills, systems, and institutions within a wider social and cultural enabling environment" (UNISDR, 2009, p. 6) - whilst placing emphasis on Alaerts and Kaspersma's (2010) focus on the importance of knowledge production - i.e. the collation and synthesis of knowledge - as a key component of capacity development. Hence, key outputs of the project include the development of knowledge products that describe best practices suitable for each of the CATALYST regions, identify gaps in research and existing networks, and outline recommendations for how to foster capacity development to strengthen DRR/CCA in those regions.

\section{The CATALYST Think Tank}

The added value of the CATALYST project is its Think Tank, which, by the end of the project, was composed of over 120 regional experts from the four CATALYST regions. These regional experts were from inter-governmental, governmental and non-governmental organisations, the scientific community and the private sector. They worked together with the CATALYST project partners in a collective effort to develop the key knowledge products and, by doing so, to ensure that the project's knowledge products were useful to their own work and that of others in these regions. The chosen approach to the selection of experts to become Think Tank members (TTM) combined an initial stakeholder analysis (described in Mysiak et al., 2012) and a subsequent "snowball" approach, i.e. individuals and organisations initially identified as suitable members in the stakeholder analysis (based on interest in cooperation, level of expertise and organisational mandate among other criteria), and then identified further potential members. In addition, as subsequent work generated further interest, the project was able to attract more members. It is important to note that the experts have been largely self-selecting since there was no payment for participation in the Think Tank. Membership, in what was often a timeconsuming process, was voluntary. The fact that this voluntary membership increased from around 50 to over 100 during the lifetime of the project suggests that the project was seen as relevant and of value to regional experts.

The CATALYST Think Tank was global in extent but regional in implementation. It was not the intention of the project to provide a "one-size-fits-all" set of knowledge products, nor to promote a Euro-centric view of what other regions of the world may need in terms of DRR and CCA capacity development; rather the intention was to allow regional experts to define the needs and best practices of their own region - a process for the regions, by the regions. The participatory and expert-driven nature of the Think Tank meant that not all hazards were treated equally and to the same extent. CATALYST can be described as a necessarily biased process that followed the interests of our regional experts in order to specify the hazards to be discussed in each region, and to determine the extent to which they should be examined. In the European Mediterranean region, the key themes were flood, drought and earthquake risk management; in the South and Southeast Asian regions it was floods, earthquake and tsunami risk management; in Central America and the Caribbean the emphasis was on ecosystemsbased DRR/CCA, social vulnerability, and the follow-up to the Hyogo Framework for Action; and in the East and West Africa regions, the main thematic focus was on urban disaster risk reduction, including floods.

Since CATALYST was not an FP7 research project, but a coordination action, it did not seek to carry out a formal analysis of practices to determine which were "best" and which were not. It based its identification of best practices on the opinions of Think Tank members based on their own experiences, and those of the countries in which they work. As such the project should be seen as complimentary to, and not a replacement for, work done by organisations such as UNISDR on analytically identifying best practices. CATALYST was, however, aware that the very concept of "best" depends considerably on what practice is appropriate to the governance structure, culture and needs of a specific country or locality (see Sect. 4). Knowing that not all best practices would be transferable to all regions or countries, the project ensured that information was collated in its regional Best Practice Papers with attention to impediments to implementation and limits to the applicability of practices described (see the four regional CATALYST Best Practice Paper series entitled "Before Disaster Strikes: Transformations in practice and policy", available at: 


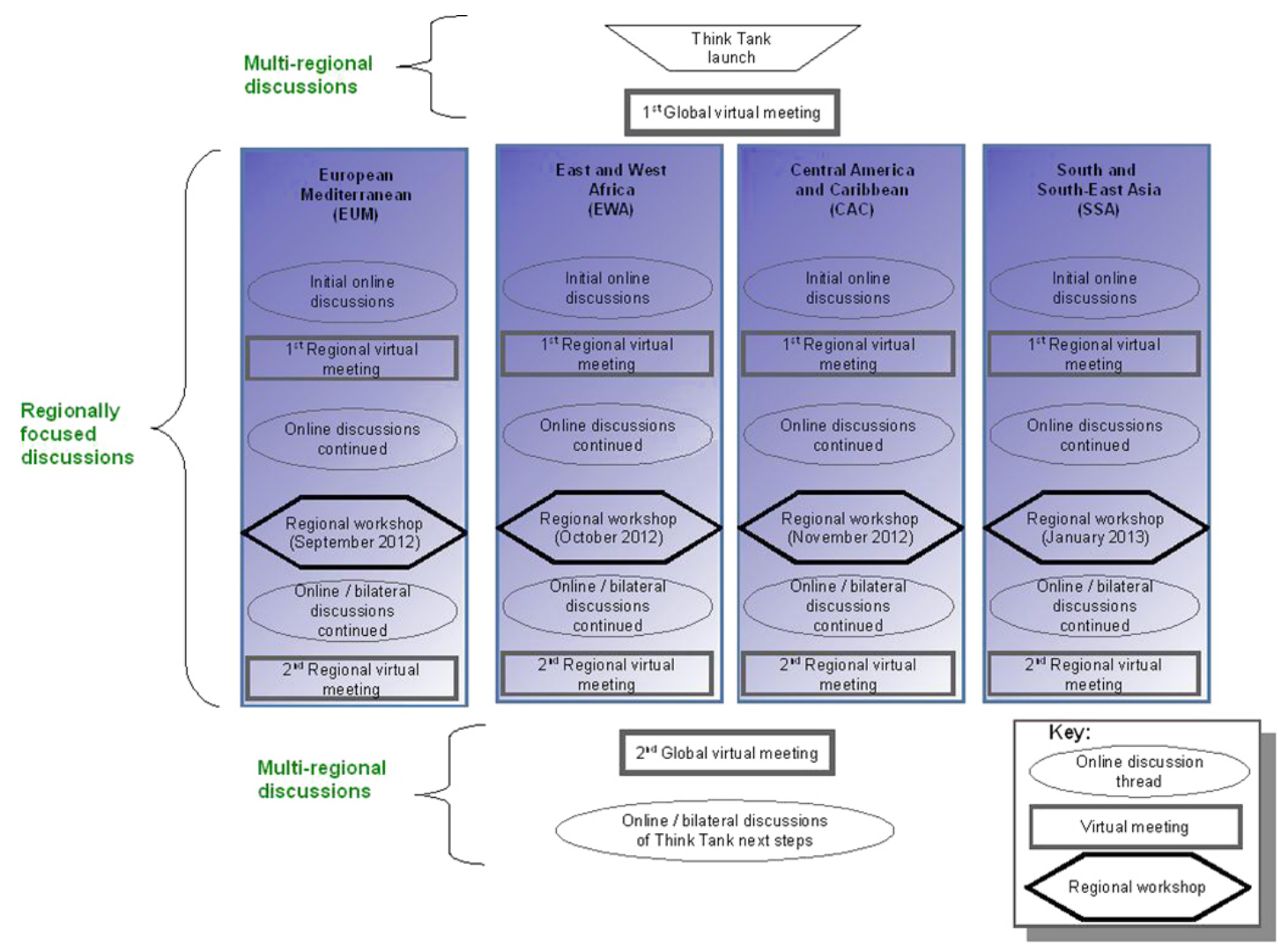

Figure 2. The CATALYST Think Tank process 2012-2013.

http://www.catalyst-project.eu/07public-dl.html\#a08). Additionally, the project focused on discussions on best practices, rather on poor ones, to encourage open discussion of experiences between experts, and through these discussions the project was in a position to infer less effective or poor practices.

\subsection{Think Tank process}

The Think Tank sought to catalyse both intra- and interregional exchange of knowledge and ideas. As a result, the Think Tank process - see Fig. 2 - has both multi-regional (Think Tank members from all regions) and regional discussion processes (members work with their regional colleagues). Whether regionally or multi-regionally, the Think Tank members in CATALYST are able to share and discuss issues with each other via online discussions, regional and multi-regional virtual meetings, interviews, face-to-face bilateral meetings and regional workshops.

After an interview round with selected TTM to begin to identify key issues within the four regions, the CATALYST Think Tank was launched by a virtual "kick-off" meeting of the multi-regional Think Tank, in spring 2012, permitting members to exchange first experiences and to clarify the goals of the project and their role in the Think Tank. The process then divided into four regional sub-processes for each of the project regions (see Fig. 2). Each regional sub-process began with online discussions to confirm the key thematic issues of importance to the region and to identify initial perspectives on gaps in knowledge. These discussions were swiftly followed by regional virtual meetings to permit the Think Tank members to discuss these thematic issues and therefore to prepare the thematic discussions to be held at the regional workshops. Prior to the regional workshops, two knowledge products were developed: a report on issues, gaps and opportunities in the regions, and a report on capacity development for disaster risk reduction and adaptation. These reports were fed into regional workshops on best practices and knowledge gaps that took place between September 2012 and January 2013 in Italy, Ethiopia, Jamaica and Thailand (see Fig. 3)

Based on the results of these workshops, the regional processes concluded with a second set of regional virtual meetings and bilateral meetings at international conferences, such as the UNISDR Global Platform, the Asia Pacific Water Summit in Chiang-Mai, and the 5th Delft Symposium on Water Sector Capacity Development, in the Netherlands, to confirm the findings of the workshops and thereby support the development of (i) the CATALYST regional workshops reports, (ii) a synthesis report on best practices, research gaps and recommendations for fostering capacity development in 


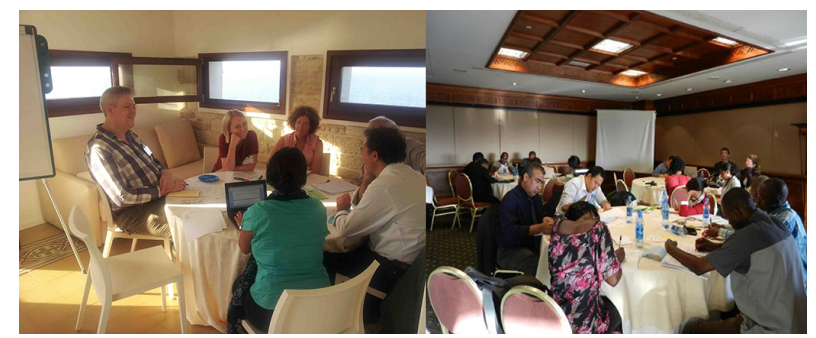

Figure 3. Some of the Think Tank members in discussion at the CATALYST regional workshops for the European Mediterranean, held in Italy (left), and for East and West Africa, held in Ethiopia (right), in 2012.

the regions, and (iii) a set of best practice papers focused on each region.

The last part of the Think Tank process has involved a final multi-regional virtual meeting to present results, gain feedback from TTM, and discuss the follow-up to CATALYST. In addition, interviews have taken place with selected members to gather their personal views on how policy should be adapted to support their sector's work in DRR/CCA, thus contributing to the Special Report on Stakeholder Advice to Policy Makers (Hare, 2013).

\section{Capacity development recommendations emerging from the Think Tank}

As highlighted by the IPCC (2012), we often do not take advantage of our knowledge about the management of risks related to natural hazards. To be more specific, we know that governance has a major role to play in DRR (UNISDR, 2004, 2007; ESCAP/UNISDR, 2012) and is one element of the type of social capacities that need to be further developed in all parts of the world in order to improve DRR (Kuhlicke et al., 2011). The following examples of recommendations from Think Tank members reveal different aspects of the various roles governance plays in DRR, e.g. as an enabler for the mainstreaming of DRR and CCA into policy- and decisionmaking across sectors; as a constraining factor in the type of capacity development that is best provided at the country/local level; as a formal institutional environment for supporting the re-linking of urban and rural populations as joint actors in DRR; and as a creator of an enforcement environment that can better support the use of ecosystem services for DRR. In future publications, the CATALYST project will describe more recommendations by the Think Tank members in detail.

\subsection{Mainstreaming DRR and climate change adaptation into policy frameworks}

CATALYST Think Tank members are discussing ways of fostering capacity development to support the integration of DRR and climate change adaptation into sectoral planning activities, especially in urban land-use planning, and ecosystem management, as well as providing alternative best practice models on how to integrate the activities of government departments into mainstream DRR cross-sectorally. The better coordination of DRR and CCA activities and practitioners (that would, for example, support improved inter-connectivity between disaster relief planning and longterm climate change adaptation) is seen as very important, but members have recommended that it should not involve the creation of new networks. In East and West Africa, more coordinated regional platforms and centres of excellence would be useful. A further recommended approach is to integrate DRR provisions better into National Adaptation Programmes of Action (so-called NAPAs: the formal identification and communication of urgent activities and projects needed to reduce vulnerability in the face of climate change (UNFCCC, 2001)), not dissimilar to the way countries such as Bangladesh and Viet Nam have already integrated DRR and CCA into national development strategies (ESCAP/UNISDR, 2012).

\subsection{Avoiding the trap of unintended policy consequences}

Some Think Tank members have stressed that DRR needs to be integrated even into sectoral planning decisions that may appear tangential to risk reduction. One example from the Central American and Caribbean region is the manner in which policy decisions related to free-trade agreements that open up small-scale farming systems to international competition can drive migration into the cities from rural areas and lead in turn to higher social, economic and physical vulnerability of those migrants now in rapidly expanding urban environments beset by natural hazards. Capacity development needs to be aimed at policy makers across the sectors if such indirect increases in vulnerabilities are to be taken into account during planning.

\subsection{Different governance structures require tailored ca- pacity development activities}

It has been pointed out by Think Tank members that it is often difficult to transfer best practices from one country to another due to differences, not only in culture and language, but also most importantly in governance structures (Jaspers et al., 2012). This means that capacity development must ultimately be tailored to specific governance contexts within a country if it is to have maximum value. Analysis undertaken by CATALYST of training provision in the different regions (Jaspers et al., 2012) suggests that training offers are dominated by large, regional providers (e.g. universities or UN bodies). If this is the case, a challenge for these regional providers and funding agencies is how to ensure that specific country-level/local capacity development is explicitly 
provided, whilst still providing general training on DRR and climate change adaptation. This should lead to more sophisticated multi-level approaches towards DRR capacity development policy in this area, an issue which the South and Southeast Asia members are considering.

\subsection{Re-linking urban and rural communities}

In order to strengthen resilience in the face of natural hazards it is important to refashion the link between rural and urban communities. To do so, European Mediterranean Think Tank members, for example, have suggested that institutional arrangements be set up so that urban areas provide financial compensation for losses suffered by rural farmers as a result of floods and droughts. Additionally, green water credits could be implemented by which water consumers like cities, irrigated areas and drinking water companies subsidise soil and water conservation in the watershed (e.g. in Kenya). Another example of suggestions is that rainwater capture in urban areas could be encouraged and used to supply nearby agricultural areas in times of drought. These could all be considered examples of what Gutman (2007) has called the vitally important "new rural-urban compact" for sustainability.

\subsection{Carrots and sticks, and ecosystem services for DRR}

As has been mentioned, there is an interest amongst some Think Tank members, e.g. in the Central America and Caribbean region, in integrating ecosystem services into DRR, for which there are governance implications. They have pointed out that often even when there are laws in place to protect ecosystems such that they can support the reduction of vulnerability to natural hazards, enforcement is often weak. Without enforcement, policy makers are left with only half the possible management tools to choose from: incentives, carrots, but no sticks (a problem noted by the Think Tank members of the East and West Africa region as well). Capacity development should also focus on supporting institutional and organisational development to improve enforcement capabilities at the national and local level.

\section{Lessons learned from running a multi-regional think tank}

A significant indicator of stakeholder confidence in the project is the fact that Think Tank membership grew steadily over the lifetime of the project. Its members also continued to collaborate with the CATALYST partners until the end of the project in the development of knowledge products, by providing feedback on them, as well as providing background information, and even going so far as to co-author essays (see for example, the "Best Practices Notebook for DRR and CCA" available at: http://www.catalyst-project.eu/ 07public-dl.html\#a09). Given that membership was unpaid and voluntary, the CATALYST project had to continue pro- viding outputs of use to the members or else risk losing their participation. Stakeholder evaluations carried out in the middle and at the end of the project confirm the positive view of the project held by members. The clear majority of respondents to the evaluations $(n=17$ for the mid-term report and $n=12$ at the end of project) had read the key CATALYST products developed so far and found them useful for their current work. However, there have been some challenges to face, and lessons learned.

\subsection{Each tool for communication and exchange has a different role to play}

Although virtual meetings between Think Tank Members (TTM) were not so effective for eliciting expansive knowledge, they were irreplaceable as a means of maintaining stakeholder interest in the Think Tank and for keeping up information exchange during phases in which there were no workshops. In the CATALYST project, it was found that online discussions could not, as originally intended, play this role that was finally taken up by virtual meetings, and went largely unused by the TTM shortly after launch. Such discussions were replaced by the convening of more virtual meetings with the TTM. An online discussion forum needs both ongoing facilitation and a great deal of stakeholder motivation in order to be maintained. The CATALYST TTM were all volunteers working in their own time, and simultaneously, busy in their professional work. This precluded the maintenance of such a forum. More research is needed on the conditions for a successful online discussion forum. In the final virtual meeting of the CATALYST Think Tank, a TTM suggested that moving away from a website-based forum to an email-based one, or one with instant social media messaging to alert TTM of new discussion threads and inputs, might have improved the use of the forum (Hare and van Bers, 2013). Finally, it is vitally important to make use of interviews and bilateral meetings with TTM, in order to get in-depth information and expertise from stakeholders that are not able to be elicited from workshops or virtual meetings. The amount of rich information that one can elicit from interviews is demonstrated in the Special Report on Stakeholder Advice to Policy Makers (Hare, 2013).

\subsection{There is no replacement for meeting in person}

Whilst there is a temptation to rely on virtual communication for developing and maintaining networks, there can be no substitute for creating opportunities for allowing network members to meet in person, e.g. through workshops. Such meetings create trust and bonds, and support the sharing of knowledge. As a means of eliciting substantive information from groups, they are second to none. The CATALYST project organised just one workshop per region, at the midpoint of the project, whilst making use of virtual meetings, online discussions, bilateral talks, and other events to 
create and maintain the Think Tank. In future projects, those involved in this project recommend that an additional workshop is organised in each region at the beginning of the project in order to get to know the stakeholders better and to create bonds and trust between the members at an earlier stage.

\subsection{Multi-regional virtual meetings are a great idea, but hard to implement}

It is difficult to organise a common time for a virtual meeting that includes stakeholders from Central America, Europe, Africa and Asia. The different time zones do not permit it. For CATALYST, it was therefore best to organise virtual meetings regionally.

\subsection{Starting locally and working up to the regions}

It has been an issue since the beginning of the project, as mentioned by the Think Tank and project partners, that working at the regional level (Hare and van Bers, 2013) was not going to provide knowledge products of immediate use at the local level (see Sect. 3). If replanning this project with the goal of providing regional exchange of best practices relevant to the local level, then CATALYST could have also in theory started at the national level by first working with experts from one country, gathering the state-of-the-art and best practices there, and then selecting and working in another. Once enough country-level insights are collected, then regional exchange and synthesis could begin.

Not being able to start the project again, the CATALYST project responded to the issue of local relevance on the one hand by trying to expand membership of the Think Tank to more local- or country-level experts. On the other hand, it is also hoped that after the conclusion of the project in September 2013, country-specific CATALYST projects can be set up with local stakeholders to interpret and transfer the best practices identified at the regional level by CATALYST to practicable solutions at the country/local level, with an emphasis on adaptive governance, i.e. "the ability of governance systems to recover from shocks, making transformative change possible“ (ESCAP/UNISDR, 2012: p. xxvi).

Acknowledgements. CATALYST is a project funded by the European Commission Seventh Framework Programme FP7 (FP7/2007-2013) under grant agreement 283177. Any opinions mentioned in this communication are those of the project and not necessarily those of the European Commission. We would like, of course, to thank the involvement of our Think Tank members, without whom the project would not be possible. If you require more information about the CATALYST Think Tank, please email info@catalyst-project.eu or visit the website www.catalyst-project.eu.

Edited by: A. Steinführer

Reviewed by: two anonymous referees

\section{References}

Alaerts, G. J. and Kaspersma, J. M.: Progress and challenges in knowledge and capacity development, in: Capacity Development for Improved Water Management, edited by: Blokland, M., Alaerts, G., Kaspersma, J., and Hare, M., CRC Press - Taylor \& Francis Group: Delft, 2010.

ESCAP/UNISDR: Reducing Vulnerability and Exposure to Disasters - The Asia-Pacific Disaster Report 2012, ESCAP/UNISDR report, 134 pp., 2012.

Gutman, P.: Ecosystem services - foundations for a new rural-urban compact, Ecol. Econom., 62, 383-387, 2007.

IPCC: Managing the Risks of Extreme Events and Disasters to Advance Climate Change Adaptation, A Special Report of Working Groups I and II of the Intergovernmental Panel on Climate Change, edited by: Field, C. B., Barros, V., Stocker, T. F., Qin, D., Dokken, D. J., Ebi, K. L., Mastrandrea, M. D., Mach, K. J., Plattner, G.-K., Allen, S. K., Tignor, M., and Midgley, P. M., Cambridge University Press, Cambridge, UK, 582 pp., 2012.

Hare, M. (Ed): CATALYST Special Report on Stakeholder Advice to Policy Makers, CATALYST Project, Deliverable 4.4., 37 pp., available at: http://www.catalyst-project.eu/07public-dl. $\mathrm{html}$ and soon to be reprinted, with more interviews, as a United Nations University Policy Brief, 2013.

Hare, M. and van Bers, C. (Eds): CATALYST Regional workshop reports. CATALYST Project, Deliverable 4.2., 175 pp., available at: http://www.catalyst-project.eu/07public-dl.html, 2013.

Jaspers, F., Hare, M., van der Keur, P., Luther, J., Calliari, E., and Daniel, H.: Report on Capacity Development for Disaster Risk Reduction, CATALYST Project, Deliverable D3.1., 137 pp., available at: http://www.catalyst-project.eu/07public-dl. html, 2012.

Kuhlicke, C., Steinfuehrer, A., Chloe, B., Bianchizza, C., Bründl, M., Matthias, B., De Marchi, B., Di Masso Tarditti, M.; Höppner, C., Komac, B., Lemkow, L., Luther, J., McCarthy, S., Pellizzoni, L., Renn, O., Scolobig, A., Supramaniam, M., Tapsell, S., Wachinger, G., Walker, G., Whittle, R., Zorn, M., and Faulkner, H.: Perspectives on social capacity building for natural hazards - outlining an emerging field of research and practice in Europe, Environ. Sci. Pol., 14, 804-814, doi:10.1016/j.envsci.2011.05.001, 2011.

Mysiak, J., Calliari E., Carrera L., Maziotis A.,Van Der Keur P., Luther J., and Kuhlicke C.: CATALYST Report on Issues, Gaps and Opportunities, Network Coverage, CATALYST Project, Deliverable 2.2., 76 pp., available at: http://www.catalyst-project. eu/07public-dl.html, 2012.

O’Brien, K., Sygna, L., Leichenko, R., Adger, W. N., Barnett, J., Mitchell, T., Schipper, L., Tanner, T., Vogel, C., and Mortreux, C.: Disaster Risk Reduction, Climate Change Adaptation and Human Security. Report prepared for the Royal Norwegian Ministry of Foreign Affairs by the Global Environmental Change and Human Security (GECHS) Project, GECHS Report 2008:3, Oslo available at: http://www.preventionweb.net/ files/7946_GECHSReport3081.pdf, 2008

UNFCCC: Guidelines for the preparation of national adaptation programmes of action, UNFCCC Decision 28/CP.7, available at: http://unfccc.int/resource/docs/cop7/13a04.pdf\#page=7, 2001.

UNISDR: Disaster Risk Reduction, Governance and Development, UNISDR Africa Educational Series, Vol. 2, 56 pp., 2004. 
UNISDR: Hyogo Framework for Action 2005-2015 - Building the Resilience of Nations and Communities to Disasters, UNISDR report, 25 pp., 2007.
UNISDR: 2009 UNISDR Terminology on Disaster Risk Reduction, available at: http://www.unisdr.org/files/7817 UNISDRTerminologyEnglish.pdf, 30 pp., 2009. 